\title{
Contribution of peat compaction to relative sea-level rise within Holocene deltas
}

\author{
S. van Asselen, ${ }^{1}$ D. Karssenberg, ${ }^{1}$ and E. Stouthamer ${ }^{1}$ \\ Received 28 September 2011; revised 9 November 2011; accepted 10 November 2011; published 20 December 2011.
}

[1] Modern and forecasted flooding of deltas is accelerated by subsidence of Holocene deposits. Subsidence caused by tectonics, isostasy, sediment compaction and anthropogenic processes, combined with eustatic sea-level rise, results in drowning and increased flood risk within densely populated deltas. Many deltaic sedimentary successions include substantial amounts of peat, which is highly compressible compared to clay, silt and sand. Peat compaction, therefore, may contribute considerably to total delta subsidence. Existing studies are inadequate for quantifying peat compaction across deltas. We present a numerical peat compaction model calibrated with an extensive field dataset. The model quantifies spatial and temporal trends in peat compaction within fluvial-dominated Holocene flood basin sequences of different compositions. Subsidence due to peat compaction is highly variable in time and space, with local rates of up to $15 \mathrm{~mm} / \mathrm{yr}$, depending on sedimentary sequence. This is extremely important information for developing sound delta management strategies. Artificial groundwater table lowering may cause substantial additional subsidence. Subsidence due to peat compaction might even exceed estimates of relative sea-level rise, and thus, may seriously increase the risk of delta drowning and human vulnerability to flooding. Citation: van Asselen, S., D. Karssenberg, and E. Stouthamer (2011), Contribution of peat compaction to relative sea-level rise within Holocene deltas, Geophys. Res. Lett., 38, L24401, doi:10.1029/ 2011GL049835.

\section{Introduction}

[2] Subsidence is a critical control on deltaic processes [van Asselen et al., 2009]. Many deltaic sequences include substantial amounts of peat, with peat compaction representing a fundamental control on subsidence. Field studies show that millennia-averaged peat compaction rates in Holocene sequences of up to tens of meters thick, are locally up to $5 \mathrm{~mm} / \mathrm{yr}$ [Bloom, 1964; Haslett et al. 1998; Edwards, 2006; Long et al., 2006; Törnqvist et al., 2008; Horton and Shennan, 2009]. Similar rates are also estimated over $\sim 100$ years in relatively thin (up to $\sim 4 \mathrm{~m}$ ) Holocene sequences [van Asselen et al., 2010]. A major concern with estimating compaction rates based solely on field data from boreholes is that such observations represent compaction at the local (point) scale. Also, the observed compaction is an averaged value over sometimes long time periods. Thus, the use of observational data alone is inadequate for

\footnotetext{
${ }^{1}$ Department of Physical Geography, Faculty of Geosciences, Utrecht University, Utrecht, Netherlands.
}

Copyright 2011 by the American Geophysical Union. 0094-8276/11/2011GL049835 understanding peat compaction over a range of temporal and spatial scales, which is fundamental to comprehending modern environmental problems within deltaic settings, in particular relative sea-level rise, which may result in damage to wetland ecosystems and increased flooding risk [e.g., Day and Giosan, 2008; Horton and Shennan, 2009]. Numerical models represent valuable tools useful for understanding and predicting peat compaction at a range of spatial and temporal resolutions. Existing models allow calculating syndepositional compaction in aggrading successions of different composition [e.g., Paul and Barras, 1998; Tovey and Paul, 2002; Meckel et al., 2007]. But, like many other peat compaction models (for an overview see van Asselen et al. [2009]) these models have critical shortcomings considering their application to Holocene fluvial-deltaic settings containing peat. Most importantly, geotechnical properties of peat are problematic to estimate because of large variations in peat properties that commonly occur over short distances within a peat succession [e.g., Lefebvre et al., 1984; Price et al., 2005]. Peat properties are usually estimated based on short-duration compression tests and laboratory analysis of limited peat samples in an already compressed state. Such analyses are unlikely to be applicable for accurately modeling peat compaction over Holocene timescales. Further, often-used empirical relations for estimating geotechnical properties are usually derived from deeply-buried clastic sediments [Sclater and Christie, 1980] and thus likely do not apply to Holocene peat, which has very distinctive geotechnical properties [Mesri and Ajlouni, 2007]. Finally, time-dependent compaction, i.e. continued compaction under conditions of constant effective stress, is seldom considered by these models.

[3] We present a new one-dimensional peat compaction model that incrementally calculates sedimentation and compaction due to an increase in stress and time in an aggrading fluvial-dominated deltaic sequence over Holocene timescales. The model is calibrated with an extensive field dataset (100 samples) from a Holocene fluvial-dominated deltaic sequence within the Cumberland Marshes [van Asselen et al., 2010], Canada, which has experienced minimum human influence. This data set ensures reliable fitting of model parameters. We use our model to extrapolate our field data to other deltaic sequences representative for other Holocene deltas. To ensure appropriate calibration of the model for various peat types found in these deltas, our field data set includes sequences with different types of peat, and calibration of our model is done for each peat type separately. To allow extrapolation to other deltaic settings, we provide model scenario runs with predefined sequences of interbedded peat and clay layers. Human impact due to groundwater lowering is predicted by modeling a reduction in pore water pressures. The uncertainty in model parameters found in the calibration of our model to the observational 


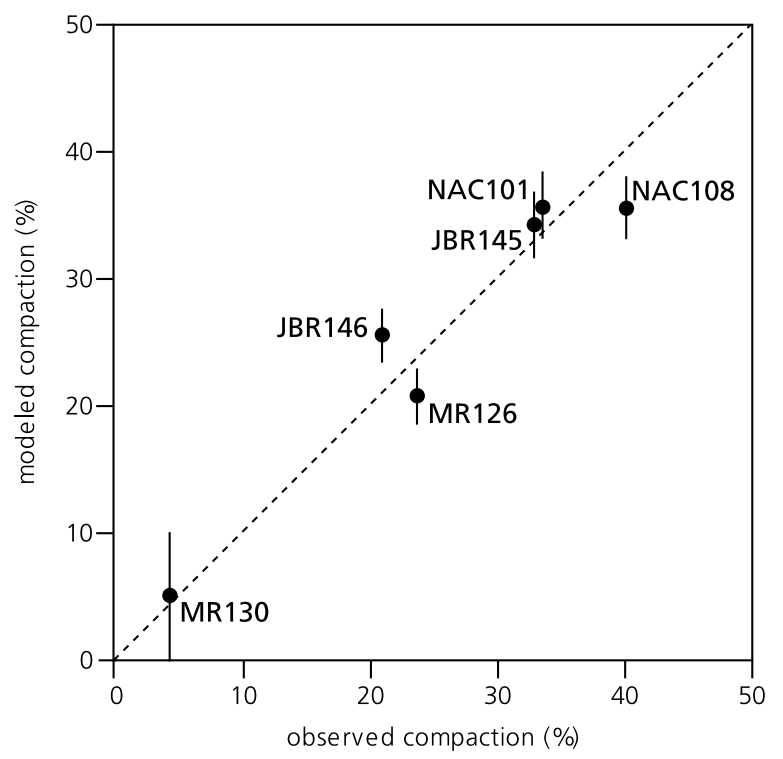

Figure 1. Plot of the modeled vs. observed compaction (\%) of the 6 cores (labels denote core codes) used for calibration, using the parameter set $c=0.09, d=0.05$ and $b=0.009$. The vertical bars represent $95 \%$ confidence intervals (Text S1, section $3 b$ and Figure S2).

data is propagated through the model when extrapolating to other depositional sequences. Thus, we can calculate confidence intervals on estimated subsidence for other deltas given our observational data.

\section{Model Description and Calibration}

[4] In the model, 5-10 $\mathrm{cm}$ thick peat and clay layers are successively added to an alluvial sequence. Each layer $i$ is characterized by an initial thickness $h_{0, i}(\mathrm{~m})$, Loss On Ignition $L O I_{i}$ (fraction of 1), which is indicative for the organicmatter content, saturated density $\rho_{s, i}\left(\mathrm{~g} / \mathrm{cm}^{3}\right)$ and time of deposition $t_{\text {dep, },}(\mathrm{yr})$. The model describes compaction of organic layers with an $L O I>0.2$ (defined as peat, based on the classification of De Bakker and Schelling [1966]). Pure clay is much less compressible than peat [Mesri and Ajlouni, 2007], and is assumed to be incompressible over the considered timescales (Figure S1 in the auxiliary material). ${ }^{1}$ This assumption may lead to an underestimation of the total amount of subsidence due to compaction. At each time step, a new layer is deposited, after which the thickness of each of the layers $i$ in the aggrading sequence is calculated using:

$$
h_{i, t}=h_{0, i} \exp \left(-\varepsilon_{i, t}\right)
$$

in which $\varepsilon_{i, t}$ is natural strain (Text S1, section 1) of layer $i$ at time $t(\mathrm{yr})$. This better describes large compressions such as occur in peat compared to linear strain [Den Haan, 1994], which is used in most existing peat compaction models. Natural strain is calculated using:

$$
\varepsilon_{i, t}=a_{i} \ln \left(\frac{\sigma_{i, t}^{\prime}}{\sigma_{0}^{\prime}}\right)+b \ln \left(\frac{t-t_{\text {dep }, i}}{t_{0}}\right),
$$

${ }^{1}$ Auxiliary materials are available in the HTML. doi:10.1029/ 2011 GL049835. in which $a_{i}$ and $b$ are calibration parameters (dimensionless), $\sigma_{i, t}^{\prime}$ is the effective stress $(\mathrm{kPa}), \sigma_{0}^{\prime}$ and $t_{0}$ are initial conditions (=1; Text S1, section 2). Also, at each time step, the total amount of surface subsidence $s_{p}(\mathrm{~m})$ is calculated as the sum of subsidence of all layers. In addition, we calculate the subsidence rate $(\mathrm{m} / \mathrm{yr})$ per time step, which is $s_{p}$ divided by the accumulation time of the youngest layer. The logarithmic relation with both stress and time in equation (2) is usually assumed in models based on soil mechanics theory [Kruse, 1998; Den Haan, 1994, 2008], based on good fits with data derived from short-duration compression tests, but is not necessarily valid over longer geological timescales. Therefore, linear and power formulations were also evaluated in the calibration step, and rejected because fits between observed and modeled values were worse (Text S1, section 3).

[5] The effective stress is calculated based on Terzaghi's principle of effective stress [Terzaghi, 1943] (Text S1, section 4). The value of $a_{i}$ is linearly related with $L O I_{i}$, as has been determined based on results from compression tests [Kruse, 1998; Den Haan, 1994]:

$$
a_{i}=c L O I_{i}+d .
$$

[6] Parameters $b, c$ and $d$ are calibrated using field data from the Cumberland Marshes. Here, in the 1870s an avulsion of the Saskatchewan River invaded a peatland, thereby partly burying an up to $\sim 2$-m-thick Late Holocene fen peat layer overlying an incompressible substrate, by up to $\sim 2$ m thick alluvium [e.g., Smith et al., 1998; Morozova and Smith, 2003]. Data from six cores obtained from this area [van Asselen et al., 2010] were used to generate the model calibration dataset (Text S1, section 5). Using this dataset $\left(h_{0}, L O I, \rho_{s}\right.$ and $t_{\text {dep }}$ of each 5-cm-thick layer), parameters $b, c$ and $d$ were calibrated by minimizing the objective function:

$$
\Phi=\sum_{i=1}^{n}\left(h_{i, \text { ndtime }}-h_{i, o b s}\right)^{2}
$$

with, $h_{i, \text { endtime }}$ and $h_{i, o b s}$, the modeled and observed final thickness of layer $i$, respectively. Calibration was done by an exhaustive search in parameter space (Text S1, section 3a), resulting in the parameter set $c=0.09, d=0.05$ and $b=$ 0.009 with the lowest value of the $\Phi$. This parameter set results in a good fit between observed and modeled sequences (Figures 1 and S2), and was used in subsequent model runs, calculating 95\% confidence intervals [Seber and Wild, 2003; Doherty, 2004] (Text S1, section 3b).

[7] The calibrated model is used to calculate past and present rates and amounts of subsidence due to compaction of a peat succession overlain by a clay succession (overburden), for different scenarios regarding duration of peat accumulation $\left(t_{p}\right)$, duration of overburden deposition $\left(t_{c}\right)$, $L O I$ of peat and percentage of intercalated 5-cm-thick clay layers $\left(C_{i n t} ;\right.$ percentage of $\left.t_{p}\right)$. Two consecutive situations are considered: constant base-level rise and constant aggradation. Situation 1 represents the natural Holocene situation, during which a peat and overburden succession is successively formed. It is assumed that vertical accommodation space created by peat compaction after deposition of a new layer is filled by increased peat formation or clay deposition during the next time step. The level to which increased 


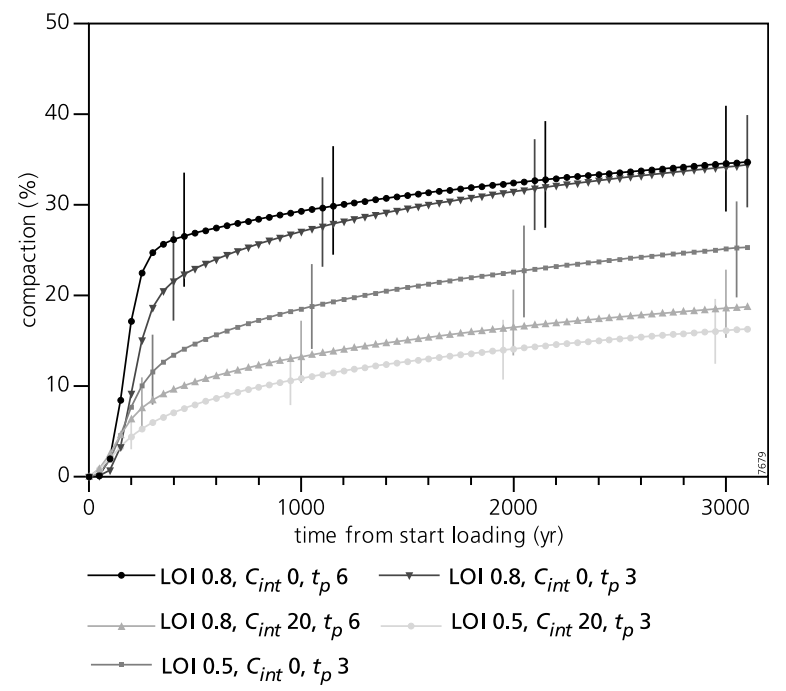

Figure 2. The amount of compaction (\%) over time after loading of peat sequences varying in thickness, $L O I$ and percentage of intercalated clay layers $\left(C_{i n t} ; t_{p}=\right.$ initial thickness peat layer in m; Situation 1). Dots represent data points and vertical bars represent $95 \%$ confidence intervals.

sedimentation or peat formation fills up accommodation space is determined by the rate of base-level rise, which is set to $0.001 \mathrm{~m} / \mathrm{yr}$. This is a fair average value representative for the period of approximately $7000 \mathrm{yr}$ BP onwards, during which most modern deltas are formed, although local conditions may cause considerable deviations from this average value [e.g., Lambeck and Chappell, 2001]. Situation 2 represents reduced aggradation rates currently observed in many deltas, caused for example by upstream damming and channel embankments [Ericson et al., 2006; Day and Giosan, 2008; Blum and Roberts, 2009; Syvitski et al., 2009] (Text S1, section 6). The effect of this has been

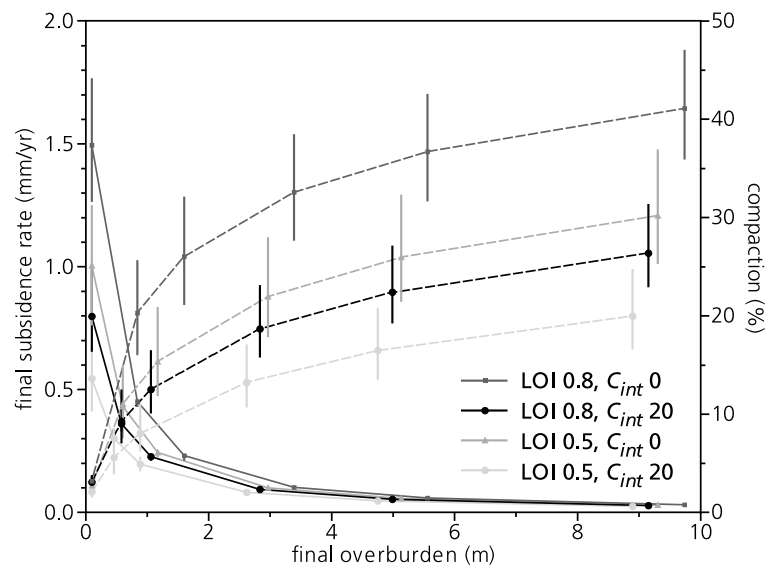

Figure 3. Plot of the percentage of peat compaction and final average subsidence rate vs. final overburden thickness, in a peat sequence with an uncompacted thickness (i.e., base-level rise multiplied by time of peat accumulation) of $4 \mathrm{~m}$ (Situation 1), and 100 years of constant aggradation of $0.001 \mathrm{~m} / \mathrm{yr}$ during Situation 2 (symbol list in Text S1). The solid lines denote final subsidence rate, the dashed lines denote percentage of compaction. Vertical bars represent $95 \%$ confidence intervals. simulated by assuming 100 years of constant clay aggradation after a sequence has built up under Situation 1. A relatively low constant aggradation rate during a time step may result in the inability to infill accommodation space created by peat compaction and base-level rise.

\section{Modeling Results}

[8] Model results show that most compaction occurs within a few centuries after the start of overburden deposition, but continues over time at a subdued rate (Figure 2, Situation 1). The amount of subsidence due to peat compaction at any moment in time is positively related with the thickness and $L O I$ of the peat sequence, and negatively related with $C_{i n t}$ (Figure 2 and Text S1, section 7). The model predicts average subsidence rates of up to $15 \mathrm{~mm} / \mathrm{yr}$ in 8-m-thick peat sequences with $L O I=0.8$. Such $L O I$ values are common in fluvial-dominated deltas [e.g., van Asselen et al., 2010].

[9] The total amount of compaction of a peat sequence is positively related with the final overburden thickness (Figure 3) [cf. Edwards, 2006; Törnqvist et al., 2008; Horton and Shennan, 2009]. However, the present rate of subsidence

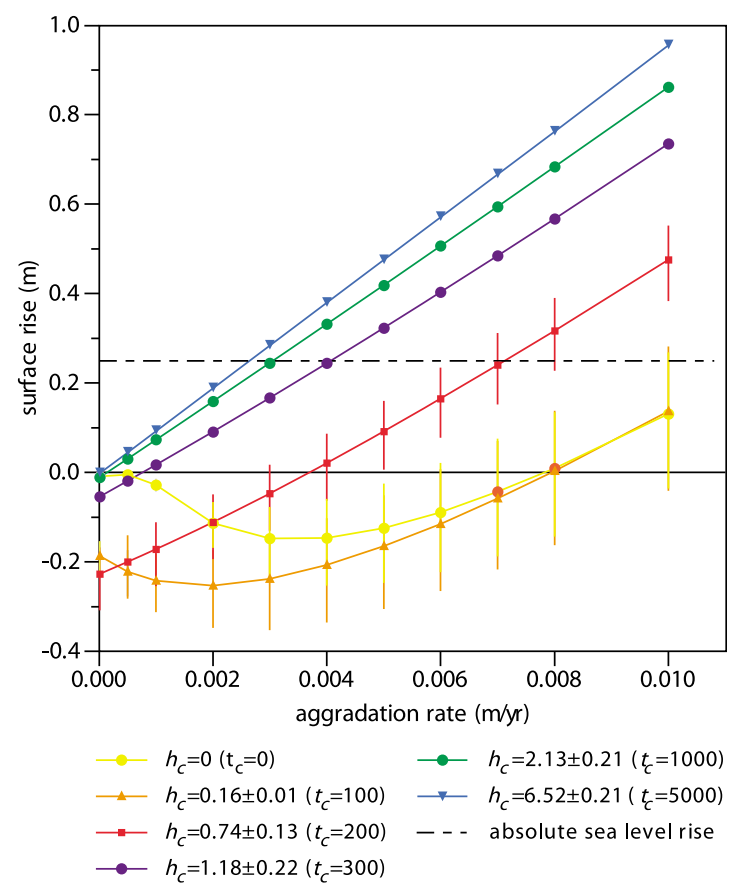

Figure 4. Plot of final surface elevation rise vs. aggradation rate after 100 years of constant aggradation (Situation 2), in an initially 4-m-thick peat layer ( $L O I 0.8)$ that was subsequently loaded by a clay layer with thickness $h_{c}$ (deposited during a period of overburden deposition in Situation $1 ; t_{c}$ in years). Negative values indicate subsidence. Maximum and minimum $h_{c}$ are given in the figure legend and are introduced by using different calibration parameter sets. The intercalated line denotes global mean sea-level rise, based on estimated rates averaged over the period 2003-2008 [Cazenave et al., 2008]. The Intergovernmental Panel on Climate Change (IPCC) predicts a global mean sea-level rise of $0.2-0.5 \mathrm{~m}$ in 2100 [Bindoff et al., 2007]. Besides compaction, relative sea-level rise depends on other local factors as glacio-isostasy and tectonics. Symbol list in Text S1. 


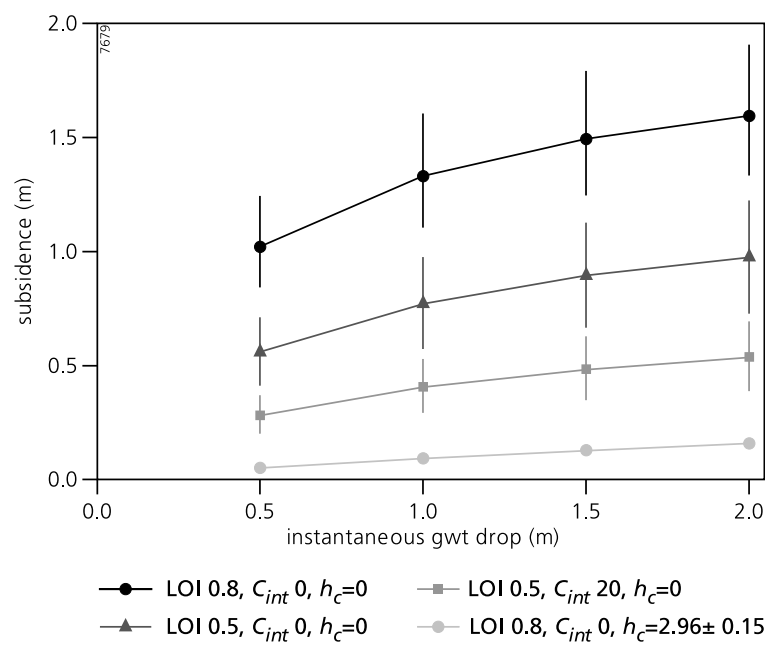

Figure 5. The amount of subsidence following instantaneous lowering of the groundwater table (gwt), for different peat sequences with an initial thickness of $6 \mathrm{~m}\left(h_{c}=\right.$ overburden thickness in m) that built-up under Situation 1. Symbol list in Text S1.

due to peat compaction is negatively related with the final overburden thickness; most compaction has occurred shortly after the start of overburden deposition. Hence, in areas where a peat layer is covered by an adequately thick clastic sediment layer $\left(h_{c}>\sim 1 \mathrm{~m}\right)$, low aggradation rates in Situation $2(\sim 0.001 \mathrm{~m} / \mathrm{yr})$ are sufficient to prevent subsidence due to peat compaction (Figure 4). However, in areas where the clastic layer is thin (few decimeters) or absent, high aggradation rates are needed to prevent subsidence due to peat compaction (Situation 2). In scenarios $h_{c}=0$ and $h_{c}=$ 0.16 (Figure 4), aggradation initially causes a large amount of peat compaction, resulting in net subsidence. An optimal aggradation rate exists for which the amount of subsidence is maximal; lower rates do not sufficiently increase the effective stress causing compaction, higher rates increasingly fill up the amount of accommodation space provided by peat compaction. In scenario $h_{c}=0.74$, the sequence is still considerably subsiding at the start of constant aggradation in Situation 2; a rate of $\sim 0.004 \mathrm{~m} / \mathrm{yr}$ is needed to prevent subsidence due to peat compaction. Even higher aggradation rates are usually needed to prevent subsidence relative to local sea-level rise. In the example given in Figure 4, a rate of $>\sim 0.003 \mathrm{~m} / \mathrm{yr}$ is needed to keep up with the rate of global sea-level rise averaged over the period 2003-2008 [Cazenave et al., 2008] (other scenarios in Figure S5).

[10] In many populated deltas, additional subsidence is caused by groundwater-table lowering, which results in increased effective stress (higher $\sigma_{i, t}^{\prime}$ in equation (2)) because the pore water pressure is strongly reduced. Human-induced compaction rates may be an order of magnitude higher than natural rates [e.g., Turner, 2004; Drexler et al., 2009]. To study this, the modeled groundwater table is instantaneously lowered by up to $2 \mathrm{~m}$ at the end of overburden deposition in Situation 1 (Figure 5). The amount of subsidence following groundwater-table lowering is positively related with peat thickness and $L O I$, and is negatively related with overburden thickness; if a peat layer has already experienced considerable compaction due to loading, the additional amount of subsidence caused by groundwater table lowering will be less than in an area where the peat layer still is in a relatively uncompacted state (Figure 5).

\section{Discussion and Conclusions}

[11] The new model, developed to quantify peat compaction in Holocene alluvial sequences of different composition, demonstrates that the amount and rate of subsidence due to peat compaction in deltas is highly variable in space and time, depending on for example peat thickness, overburden thickness, percentage of intercalated clay layers and organicmatter content of peat (Figures 2-5). As our model is calibrated against peat formed in a fresh water environment, some care should be taken when applying our results to salt marsh sequences, for example because salt marsh vegetation may have a different compressibility, and compaction may be influenced by tides. A spatial and temporal variability comparable to our results has however also been documented in salt marsh studies [e.g., Allen, 2000; Edwards, 2006; Horton and Shennan, 2009], but there is still a need for comparable calibration data sets from salt marsh environments.

[12] Unlike our combined field and modeling study, studies that rely on field data only usually present local estimates that are averaged over millennia. Our modeling results demonstrate that present rates are relatively low $(<0.2 \mathrm{~mm} / \mathrm{yr}$; Figure 3$)$ if the peat layer has already experienced compaction by loading, i.e. in situations with a present thick overburden, whereas high rates (up to $\sim 15 \mathrm{~mm} / \mathrm{yr}$ ) occur within decades to a few centuries after loading a peat sequence with a thin or absent overburden. Such rates may exceed predicted rates of near-future sealevel rise (Figure 4). This study suggests that especially distal parts of deltas, where thickest peat layers occur and an overburden is often thin or absent, are most vulnerable for high amounts of subsidence due to peat compaction. Human interventions causing reduced aggradation rates and groundwater-table lowering in such areas enhances subsidence and thereby increases the risk of delta drowning (Figures 4, 5, and S5). Thus, the threat of drowning caused by subsidence due to peat compaction varies both temporally and spatially in a delta, which is vital knowledge for sustainable management of deltaic environments in the context of forecasted rates of global sea-level rise.

[13] Acknowledgments. This paper greatly benefited from comments on earlier drafts by Paul Hudson (University of Texas at Austin, USA) and Meindert Van (Deltares, The Netherlands). Theo van Asch (Utrecht University, The Netherlands), Gerard Kruse and Henk Kruse (both employed at Deltares, The Netherlands) are thanked for their contributions to developing the compaction model. This research was funded by the Netherlands Organization for Scientific Research - Earth and Life Sciences (NWO-ALW, project 814.01.014) and Utrecht University, Faculty of Geosciences.

[14] The Editor thanks two anonymous reviewers with their assistance in evaluating this paper.

\section{References}

Allen, J. R. L. (2000), Morphodynamics of Holocene salt marshes: A review sketch from the Atlantic and southern North Sea coasts of Europe, Quat. Sci. Rev., 19, 1155-1231, doi:10.1016/S0277-3791(99)00034-7.

Bindoff, N. L., et al. (2007), Observations: Oceanic climate change and sea level, in Climate Change 2007: The Physical Science Basis. Contribution of Working Group I to the Fourth Assessment Report of the Intergovernmental Panel on Climate Change, edited by S. Solomon et al., pp. 385-432, Cambridge Univ. Press, Cambridge, U. K.

Bloom, A. L. (1964), Peat accumulation and compaction in a Connecticut coastal marsh, J. Sediment. Petrol., 34, 599-603. 
Blum, M. D., and H. H. Roberts (2009), Drowning of the Mississippi Delta due to insufficient sediment supply and global sea-level rise, Nat. Geosci., 2, 488-491, doi:10.1038/ngeo553.

Cazenave, A., A. Lombard, and W. Llovel (2008), Present-day sea level rise: A synthesis, C. R. Geosci., 340, 761-770, doi:10.1016/j.crte.2008.07.008

Day, J. W., and L. Giosan (2008), Geomorphology: Survive or subside?, Nat. Geosci., 1, 156-157, doi:10.1038/ngeo137.

De Bakker, H., and J. Schelling (1966), Systeem van Bodemclassificatie voor Nederland [in Dutch], Pudoc, Wageningen, Netherlands.

Den Haan, E. J. (1994), Vertical compression of soils, Ph.D. thesis, Delft Univ., Delft, Netherlands.

Den Haan, E. J. (2008), De intrinsieke tijd in het Isotachenmodel [in Dutch], Geotechniek, 1, 34-38.

Doherty, J. (2004), PEST, Model-Independent Parameter Estimation, User Manual, 5th ed., Watermark Numer. Comput., Brisbane, Queensland, Australia.

Drexler, J. Z., C. S. Defontaine, and S. J. Deverel (2009), The legacy of the wetland drainage on the remaining peat in the Sacramento-San Joaquin Delta, California, USA, Wetlands, 29, 372-386, doi:10.1672/08-97.1.

Edwards, R. J. (2006), Mid to late Holocene sea-level change in southwest Britain and the influence of sediment compaction, Holocene, 16 , 575-587, doi:10.1191/0959683606h1941rp

Ericson, J. P., C. J. Vorosmarty, S. L. Dingman, L. G. Ward, and M. Meybeck (2006), Effective sea-level rise and deltas: Causes of change and human dimension implications, Global Planet. Change, 50, 63-82, doi:10.1016/ j.gloplacha.2005.07.004

Haslett, S. K., P. Davies, R. H. F. Curr, C. F. C. Davies, K. Kennington, C. P. King, and A. J. Margetts (1998), Evaluating late-Holocene relative sea-level change in the Somerset Levels, southwest Britain, Holocene, 8 , 197-207, doi:10.1191/095968398669499299.

Horton, B. P., and I. Shennan (2009), Compaction of Holocene strata and the implications for relative sea-level change, Geology, 37, 1083-1086, doi:10.1130/G30042A.1.

Kruse, H. M. G. (1998), Deformation of a river dyke on soft soil, Ph.D. thesis, Utrecht Univ., Utrecht, Netherlands.

Lambeck, K., and J. Chappell (2001), Sea level change through the last glacial cycle, Science, 292, 679-686, doi:10.1126/science.1059549.

Lefebvre, G., P. Langlois, C. Lupien, and J. G. Lavallée (1984), Laboratory testing and in situ behaviour of peat as embankment foundation, Can. Geotech. J., 21, 322-337, doi:10.1139/t84-033.

Long, A. J., M. P. Waller, and P. Stupples (2006), Driving mechanisms of coastal change: Peat compaction and the destruction of late Holocene coasta wetlands, Mar. Geol., 225, 63-84, doi:10.1016/j.margeo.2005.09.004.

Meckel, T. A., U. S. Ten Brink, and S. J. Williams (2007), Sediment compaction rates and subsidence in deltaic plains: Numerical constraints and stratigraphic influences, Basin Res., 19, 19-31, doi:10.1111/j.13652117.2006.00310.x
Mesri, G., and M. Ajlouni (2007), Engineering properties of fibrous peats, J. Geotech. Geoenviron., 133, 850-866, doi:10.1061/(ASCE)10900241(2007)133:7(850)

Morozova, G. S., and N. D. Smith (2003), Organic matter deposition in the Saskatchewan River floodplain (Cumberland Marshes, Canada): Effect of progradational avulsions, Sediment. Geol., 157, 15-29, doi:10.1016/ S0037-0738(02)00192-6.

Paul, M. A., and B. F. Barras (1998), A geotechnical correction for postdepositional sediment compression: Examples from the Forth Valley, Scotland, J. Ouaternary Sci., 13, 171-176, doi:10.1002/(SICI)10991417(199803/04)13:2<171::AID-JQS369>3.0.CO;2-Z

Price, J. S., J. Cagampan, and E. Kellner (2005), Assessment of peat compressibility: is there an easy way?, Hydrol. Processes, 19, 3469-3475, doi:10.1002/hyp.6068.

Sclater, J. G., and P. A. F. Christie (1980), Continental stretching: Explanation of post-mid-Cretaceous subsidence of the central North Sea Basin, J. Geophys. Res., 85, 3711-3739, doi:10.1029/JB085iB07p03711.

Seber, G. A. F., and C. J. Wild (2003), Nonlinear Regression, John Wiley, New York.

Smith, N. D., R. L. Slingerland, M. Pérez-Arlucea, and G. S. Morozova (1998), The 1870s avulsion of the Saskatchewan River, Can. J. Earth Sci., 35, 453-466, doi:10.1139/e97-113.

Syvitski, J. P. M., et al. (2009), Sinking deltas due to human activities, Nat. Geosci., 2, 681-686, doi:10.1038/ngeo629.

Terzaghi, K. (1943), Theoretical Soil Mechanics, John Wiley, New York, doi:10.1002/9780470172766.

Törnqvist, T. E., D. J. Wallace, J. E. A. Storms, J. Wallinga, R. L. van Dam M. Blaauw, M. S. Derksen, C. J. W. Klerks, C. Meijneken, and E. M. A Snijders (2008), Mississippi Delta subsidence primarily caused by compaction of Holocene strata, Nat. Geosci., 1, 173-176, doi:10.1038/ ngeo129.

Tovey, N. K., and M. A. Paul (2002), Modelling self-weight consolidation in Holocene sediments, Bull. Eng. Geol. Environ., 61, 21-33, doi:10.1007/ s100640100126.

Turner, R. E. (2004), Coastal wetland subsidence arising from local hydrologic manipulations, Estuaries, 27, 265-272, doi:10.1007/BF02803383.

van Asselen, S., E. Stouthamer, and T. W. J. van Asch (2009), Effects of peat compaction on delta evolution: A review on processes, responses, measuring and modeling, Earth Sci. Rev., 92, 35-51, doi:10.1016/j. earscirev.2008.11.001

van Asselen, S., E. Stouthamer, and N. D. Smith (2010), Factors control ling peat compaction in alluvial floodplains: A case study in the coldtemperate Cumberland Marshes, Canada, J. Sediment. Res., 80, 155-166, doi:10.2110/jsr.2010.015

D. Karssenberg, E. Stouthamer, and S. van Asselen, Department of Physical Geography, Faculty of Geosciences, Utrecht University, PO Box 80115, NL-3508 TC, Utrecht, Netherlands. (svasselen@gmail.com) 